\title{
Synthesis and Evaluation of Fluorinated Benzyl Ethers as Alternate Protecting Groups for Enhanced NMR Resolution in Oligosaccharide Synthesis
}

\author{
Ntai M Khoabane ${ }^{1,2^{*}}$, , Elizabeth J Grayson ${ }^{1}$, Alan M Kenwright ${ }^{1}$, Manoharan K Pillai ${ }^{2}$ \\ ${ }^{1}$ Department of Chemistry, Durham University, South Road, Durham DH1 3LE, United Kingdom \\ ${ }^{2}$ Department of Chemistry and Chemical Technology, The National University of Lesotho, P.O. Roma 180, Maseru, Lesotho \\ Email:nmkhoabane2@gmail.com
}

Received: 28 October 2021; Revised: 21 December 2021; Accepted: 29 December 2021

\begin{abstract}
Oligosaccharides have been playing an important role in biological systems. Synthesis of oligosaccharides requires the protection from hydroxyl groups present in the corresponding monosaccharide units. The existing methods of protection have drawbacks, including formation of anomeric mixtures, change in hydrophilicity or lipophilicity and solubility of the products, participation of the protecting groups in the reactions of the core of monosaccharide units, problems associated with chemoselectivity, regioselectivity and overall stereochemical outcomes of reactions. Additionally, there has been a spectral overlap of these protecting groups with carbohydrate core, which yielded more complex spectra. Therefore, the identification and synthesis of suitable alternative protecting groups have received attention in the oligosaccharide synthesis. The objective of the present study was to synthesize various fluorinated benzyl ethers of methyl- $\alpha$-D-mannopyronoside and to evaluate these ethers as the alternative protecting groups for enhancing NMR resolution in the oligosaccharide synthesis. Various fluorinated benzyl ethers of methyl- $\alpha$-Dmannopyronoside were prepared through the reaction of methyl- $\alpha$-D-mannopyronoside with various fluorinated benzyl bromides by using Williamson ether synthesis method. Spectral analysis of these fluorinated benzyl ethers showed that the peaks of methylene carbons shifted to a value of 10-20 parts per million (ppm) to a high field region in the ${ }^{13} \mathrm{C}$ NMR, compared to the non-fluorinated benzyl ether. As a result, the spectral complexity decreased and enhanced the spectral resolution. In this study, we concluded that fluorinated benzyl ethers could be a suitable alternative to the nonfluorinated benzyl ethers to protect the hydroxyl groups of monosaccharides in the synthesis of oligosaccharides.
\end{abstract}

Keywords: ${ }^{1} \mathrm{H}$ NMR, ${ }^{13} \mathrm{C}$ NMR, benzyl ether, fluorinated benzyl ethers, protecting groups

\section{Introduction}

Carbohydrates are classified as important in biological molecules. Oligosaccharides have exhibited important role in cell-cell interactions, which has had several positive implications. ${ }^{1-5}$ The key reaction involved in the synthesis of oligosaccharides is a bond formation between the anomeric center of a saccharide and a hydroxyl group from another sugar molecule. In order to synthesize oligosaccharides from monosaccharide units, the hydroxyl groups present in the monosaccharides have to be protected by the suitable protecting groups. Methylsulfonylethoxycarbonyl ${ }^{6}$, benzylidene

Copyright (C2022 Ntai M Khoabane, et al

DOI: https://doi.org/10.37256/fce.3120221221

This is an open-access article distributed under a CC BY license

(Creative Commons Attribution 4.0 International License)

https://creativecommons.org/licenses/by/4.0/ 
type acetals ${ }^{7}$, isopropylidene ketals ${ }^{7}, 2$-picolyl ether ${ }^{8}$, 4-acetoxy-2, 2-dimethylbutanoyl ${ }^{9}$ and many other protecting groups have previously been reported. However, the synthesis of oligosaccharides has been still one of the most difficult tasks due to several reasons. For example, the protecting groups not only do protection of functional groups of monosaccharides but also do participation reactions in the core of monosaccharide moiety directly or indirectly, which affects the overall stereochemical outcomes of reactions. ${ }^{10}$ Besides, the formation of anomeric mixtures, a large number of the same functional groups in the monosaccharides and problems associated with regioselectivity and chemoselectivity have also complicated the process of oligosaccharide synthesis. ${ }^{10-12}$ Alternatively, the protecting groups have some advantages. For example, the protecting groups can change the overall hydrophilicity or lipophilicity of the products and their solubility. ${ }^{13}$ Therefore, the selection between polar and non-polar solvents can be made to acquire NMR spectra. Additionally, the protected monosaccharides can show the enhanced resolution of ${ }^{1} \mathrm{H}$ and ${ }^{13} \mathrm{C}$ NMR peaks.

Researches on the naturally occurring oligosaccharides and their structural elucidation have previously been reported ${ }^{14,15}$ However, in the synthesis of oligosaccharides, benzyl moiety has frequently been used as the protecting group to protect the hydroxyl functions present in the monosaccharide core and structural elucidation of the synthesized oligosaccharides has been made through NMR techniques. ${ }^{15-17}$ However, the ${ }^{1} \mathrm{H}$ and ${ }^{13} \mathrm{C}$ NMR peaks of the methylene groups of benzyl moieties have been resonated in the same region as that of ${ }^{1} \mathrm{H}$ and ${ }^{13} \mathrm{C}$ NMR of monosaccharide rings. ${ }^{15-17}$ For example, the ${ }^{1} \mathrm{H}$ NMR and ${ }^{13} \mathrm{C}$ NMR chemical shift values of methylene group of the benzyl moiety have been resonated at 4.5-5.6 ppm and 72-75 $\mathrm{ppm}^{15-17}$, respectively. The ${ }^{1} \mathrm{H}$ NMR chemical shift values for anomeric and other protons of the monosaccharide ring have been resonated at 4.4-5.5 ppm and 3.0-4.2 ppm, respectively. Similarly, the ${ }^{13} \mathrm{C}$ NMR chemical shift values for anomeric and other carbons of the monosaccharide ring have been resonated at $90-100 \mathrm{ppm}$ and $65-85 \mathrm{ppm}$, respectively. These data showed that there has been an apparent spectral overlap of methylene groups of benzyl moieties and the monosaccharide rings. ${ }^{15-17}$ Furthermore, the spectral complexity will also increase with an increasing number of monosaccharide units of an oligosaccharide chain.

Therefore, the identification and synthesis of the alternative protecting groups other than a simple benzyl moiety would be required in the synthesis of oligosaccharides. These alternative protecting groups should minimize the spectral complexity and enhance the spectral resolution. Our literature search showed that the methylene carbons of pentafluorobenzyl alcohol differed in chemical shift values at approximately $20 \mathrm{ppm}$ to a high field region in the ${ }^{13} \mathrm{C}$ NMR spectra compared to the simple benzyl alcohol ${ }^{18}$ Therefore, we envisioned that the presence of fluorine atoms at various positions on the aromatic ring of benzyl moieties would cause the methylene group to resonate at a high field region in the ${ }^{1} \mathrm{H}$ and ${ }^{13} \mathrm{C}$ NMR spectra. We also envisioned that these fluorinated benzyl moieties could be the alternative protecting groups in the synthesis of oligosaccharides. Accordingly, in the present study, we synthesized various fluorinated benzyl ethers by the reaction of methyl- $\alpha$-D-mannopyronoside with various fluorinated benzyl bromides through Williamson ether synthesis method, and evaluated the protection effect of these ethers by comparing their NMR chemical shift values focusing on the benzyl and fluorinated benzyl moieties. The results are communicated in this research. To the best of our knowledge, this is the first report of this kind.

\section{Experimental details}

\subsection{Materials and methods}

Unless otherwise specified, reagents and solvents used in this study were of analytical reagent (AR) grades and were purchased from Sigma-Aldrich and/or Fluorochem. Methyl- $\alpha$-D-mannopyronoside (1) was purchased from SigmaAldrich. Silica gel (Merck 40-63 micron 60 A) was used for column chromatography. Aluminium-supported silica gel $\left(\right.$ Merck $60 \mathrm{~F}_{254}$ ) was used for analytical thin-layer chromatography (TLC). Thermo Funigan LTQ FT spectrometer and/or Waters Micromass LCT were used to acquire mass spectra. Varian Inova-500 MHz spectrometer (VNMR 6.1 C Software) with standard pulse sequences was used to record NMR spectra. The ${ }^{1} \mathrm{H}$ channel was set at $499.186 \mathrm{MHz}$ with a $90^{\circ}$ pulse width of $11.3 \mathrm{~ms} .{ }^{1} \mathrm{H}$ NMR spectra were recorded using a spectral width of $4898.7 \mathrm{~Hz}, 32$ transients and 39 $\mathrm{K}$ data points. ${ }^{13} \mathrm{C}$ NMR spectra were acquired at $125.692 \mathrm{MHz}$ with a $90^{\circ}$ pulse width of $12.9 \mathrm{~ms}$, a spectral width of $31422 \mathrm{~Hz}, 2000$ transients and $89 \mathrm{~K}$ data points, and processed using an exponential line broadening function of 0.7 Hz. ${ }^{19}$ F NMR spectra were acquired on a $400 \mathrm{MHz}$ Varian Mercury spectrometer (VNMR 6.1 C Software) run at 376 MHz. Approximately, $10 \mathrm{mg}$ of each compound was dissolved separately in $0.5 \mathrm{~mL}$ of benzene- $\mathrm{D}_{6}$ to run NMR spectra. 
Chemical shifts are reported in parts per million (ppm) and coupling constants (J) in Hertz (Hz).

\subsection{Syntheses of compounds 2-7}

Williamson ether synthesis method was employed to synthesize compounds 2-7 as standard procedure ${ }^{19}$ with a slight modification. Compound 2 was synthesized by the reaction of methyl- $\alpha$-D-mannopyronoside (1) with benzyl bromide. Briefly, the solution of $\mathbf{1}$ and benzyl bromide (8-10 equivalents) in dimethylformamide (DMF) was prepared and mixed by stirring. Sodium hydride (60\% dispersion in mineral oil) (8-10 equivalents) was added in small portions to the mixture in an argon atmosphere at $0{ }^{\circ} \mathrm{C}$. The reaction mixture was allowed to stand at room temperature followed by stirring for 16 hours. The excess sodium hydride was quenched by methanol and the volatile materials were removed. The residue thus obtained was purified by a silica gel column chromatography using a solvent mixture of hexane and ethyl acetate (9:1). Reactions were monitored by TLC using pre-coated glass plates of aluminium-supported silica gel (Merck $60 \mathrm{~F}_{254}$ ). The TLC spots were detected by being stained with a solution of cerium sulphate and phosphomolybdic acid prepared by dissolving $2.5 \mathrm{~g}$ of cerium sulphate and $6.25 \mathrm{~g}$ of hydrated phosphomolybdic acid in dilute $\mathrm{H}_{2} \mathrm{SO}_{4}(15$ $\mathrm{mL}$ of sulphuric acid in $230 \mathrm{~mL}$ deionized water). Compound 2 was obtained in $96 \%$ yield. The same procedure was followed for the synthesis of 3-7 but the synthesis was carried out by the reaction of $\mathbf{1}$ with 2, 3, 4, 5, 6-pentafluorobenzyl bromide, 2,3,5,6-tetrafluoro-(4-methoxy) benzyl bromide, 2,3,5,6-tetrafluorobenzyl bromide, 2,6-difluoro benzyl bromide and 2-fluorobenzyl bromide, respectively. Compounds 3-7 were obtained in 16\%, 20\%, 64\%, 13\% and 88\% yields respectively. Deprotection of 2-7 was carried out by reducing them separately using palladised charcoal. In general, the rate of removal was slower for 3-7 compared to 2. Each one of the deprotected monosaccharides was obtained in a pure state after the purification through a silica gel column chromatography. The purified product showed a good concordance with NMR details of 1 provided by the supplier (Sigma-Aldrich). However, less than 10\% yields were obtained in all cases even after 18 hours of reduction. The presence of electronegative fluorine atoms on the aromatic ring hindered the process of deprotection. ${ }^{20}$

\subsection{Spectral data}

Methyl- $\alpha$-D-mannopyronoside (1): Colourless solid; ${ }^{1} \mathrm{H}$ NMR $\left(500 \mathrm{MHz}, \mathrm{D}_{2} \mathrm{O}\right) ; 4.62(\mathrm{~d}, 1 \mathrm{H}, \mathrm{J}=1.5), 3.79(\mathrm{~m}, \mathrm{H}-2)$, 3.66 (dd, $1 \mathrm{H}, \mathrm{J}=9.0,3.0 \mathrm{~Hz}, \mathrm{H}-3), 3.61$ (m, H-4), 3.49 (m, H-5), 3.72 (dd, $\left.1 \mathrm{H},{ }^{3} \mathrm{~J}=11.5,5.5 \mathrm{~Hz}, \mathrm{H}-6 \alpha\right), 3.85$ (dd, 1H, $\left.{ }^{3} \mathrm{~J}=12.0,2.5 \mathrm{~Hz}, \mathrm{H}-6 \beta\right), 3.32$ (s, 3H, H-7). ${ }^{13} \mathrm{C}$ NMR (125 MHz, $\left.\mathrm{D}_{2} \mathrm{O}\right): 101.6$ (C-1), 70.9 (C-2), 71.4 (C-3), 67.4 (C-4), 73.3 (C-5), 61.8 (C-6), 54.0 (C-7) (data provided by the supplier, Sigma-Aldrich).

Methyl 2,3,4,6-tetra-O-benzyl- $\alpha$-D-mannopyranoside (2): Colourless liquid; ${ }^{1} \mathrm{H}$ NMR $\left(500 \mathrm{MHz}, \mathrm{C}_{6} \mathrm{D}_{6}\right)$ and ${ }^{13} \mathrm{C}$ NMR (125 MHz, $\mathrm{C}_{6} \mathrm{D}_{6}$ ) (Table 1 and Table 2, respectively); ESMS, $m / z 577.4[\mathrm{M}+\mathrm{Na}]^{+}$.

Methyl-(2,3,4,6-tetra-O-2, ', ', 4',5',6'-pentafluorobenzyl)- $\alpha$-D-mannopyranoside (3): Colourless liquid; ${ }^{13} \mathrm{C}$ NMR (125 MHz, $\mathrm{C}_{6} \mathrm{D}_{6}$ ) and ${ }^{1} \mathrm{H}$ NMR (500 MHz, $\mathrm{C}_{6} \mathrm{D}_{6}$ ) (Table 1 and Table 2); ${ }^{19} \mathrm{~F}$ NMR; (376 MHz, $\mathrm{C}_{6} \mathrm{D}_{6}$ ) -144.72 to -144.38 ppm (ortho), -163.60-162.55 ppm (meta), -155.22-154.04 ppm (para); ESMS, $m / z$ 937.6 [M +Na] ${ }^{+}$.

Methyl 2,3,4,6-tetra-O-(2',3',5',6'-tetrafluoro-4-methoxy)benzyl- $\alpha$-D-mannopyranoside (4): Colourless liquid; ${ }^{13} \mathrm{C}$ NMR and ${ }^{1} \mathrm{H}$ NMR (125 MHz, $\mathrm{C}_{6} \mathrm{D}_{6}$ and $500 \mathrm{MHz}, \mathrm{C}_{6} \mathrm{D}_{6}$, respectively) (Table 1 and Table 2$) ;{ }^{19} \mathrm{~F}$ NMR (376 MHz, $\mathrm{C}_{6} \mathrm{D}_{6}$ ) -144.80 to $-144.38 \mathrm{ppm}$ (meta), -140.41 to $-139.61 \mathrm{ppm}$ (ortho). ESMS, $m / z 985.2[\mathrm{M}+\mathrm{Na}]^{+}$.

Methyl 2,3,4,6-tetra-O-2,,3',5',6'-tetrafluorobenzyl- $\alpha$-D-mannopyranoside (5): Colourless liquid; ${ }^{1} \mathrm{H}$ NMR (500 $\mathrm{MHz}, \mathrm{C}_{6} \mathrm{D}_{6}$ ) and ${ }^{13} \mathrm{C}$ NMR (125 MHz, $\mathrm{C}_{6} \mathrm{D}_{6}$ ) (Table 1 and Table 2); ${ }^{19} \mathrm{~F}$ NMR (376 MHz, $\left.\mathrm{C}_{6} \mathrm{D}_{6}\right)-144.80$ to $-144.38 \mathrm{ppm}$ (meta), -140.41 to $-139.61 \mathrm{ppm}$ (ortho). ESMS, $m / z 865.1[\mathrm{M}+\mathrm{Na}]^{+}$.

Methyl 2,3,4,6-tetra-O-2',6'-difluorobenzyl- $\alpha$-D-mannopyranoside (6): Colourless liquid; ${ }^{1} \mathrm{H}$ NMR; (500 MHz, $\mathrm{C}_{6} \mathrm{D}_{6}$ ) and ${ }^{13} \mathrm{C}$ NMR (125 MHz, $\mathrm{C}_{6} \mathrm{D}_{6}$ ) (Table 1 and Table 2); ${ }^{19} \mathrm{~F} \mathrm{NMR} ;\left(376 \mathrm{MHz}, \mathrm{C}_{6} \mathrm{D}_{6}\right.$ ) (Table 1 and Table 2); -115.22 to $-115.05 \mathrm{ppm}$ (ortho). ESMS, $m / z 721.3[\mathrm{M}+\mathrm{Na}]^{+}$.

Methyl 2,3,4,6-tetra-O-2'-fluorobenzyl- $\alpha$-D-mannopyranoside (7): Colourless liquid; ${ }^{1} \mathrm{H}$ NMR $\left(500 \mathrm{MHz}, \mathrm{C}_{6} \mathrm{D}_{6}\right)$ and ${ }^{13} \mathrm{C}$ NMR (125 MHz, $\mathrm{C}_{6} \mathrm{D}_{6}$ ) (Table 1 and Table 2); ${ }^{19} \mathrm{~F}$ NMR (376 MHz, $\mathrm{C}_{6} \mathrm{D}_{6}$ ); - 119.55 to -118.59 ppm (ortho). ESMS, $m / z 649.4[\mathrm{M}+\mathrm{Na}]^{+}$. 


\section{Results and discussion}

From methyl- $\alpha$-D-mannopyronoside (1), we synthesized methyl-(2,3,4,6-tetra- $O$-benzyl)- $\alpha$-D-mannopyranoside (2), methyl-(2,3,4,6-tetra- $O-2^{\prime}, 3^{\prime}, 4^{\prime}, 5^{\prime}, 6^{\prime}$-pentafluorobenzyl)- $\alpha$-D-mannopyranoside (3), methyl-(2,3,4,6-tetra$O$-(2',3', 5',6'-tetrafluoro-4-methoxy)benzyl- $\alpha$-D-mannopyranoside (4), methyl-(2,3,4,6-tetra- $O-2^{\prime}, 3^{\prime}, 5^{\prime}, 6^{\prime}$ tetrafluorobenzyl)- $\alpha$-D-mannopyranoside (5), methyl-(2,3,4,6-tetra- $O$-2', 6'-difluorobenzyl)- $\alpha$-D-mannopyranoside (6). methyl-(2,3,4,6-tetra- $O-2$ '-fluorobenzyl)- $\alpha$-D-mannopyranoside (7). The synthesis and structures of compounds 2-7 are shown in Figure 1.
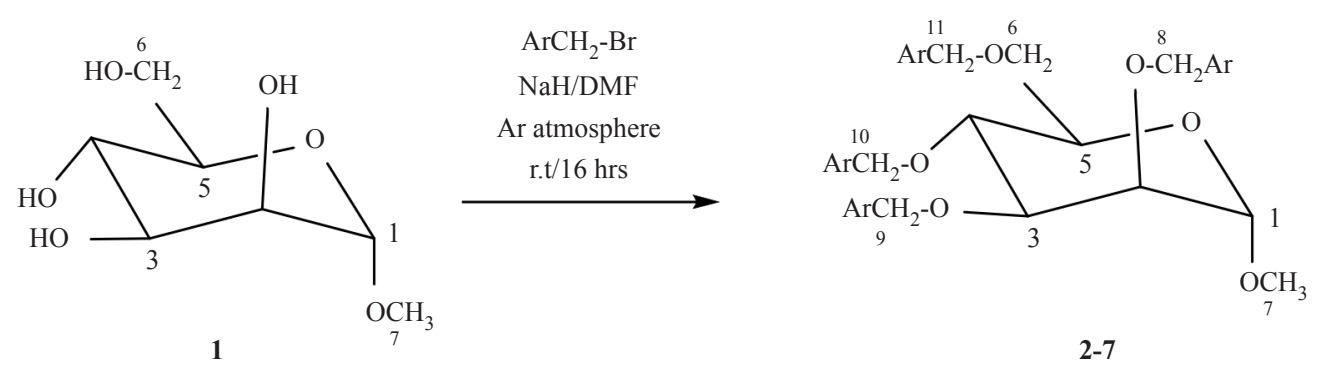

2-7

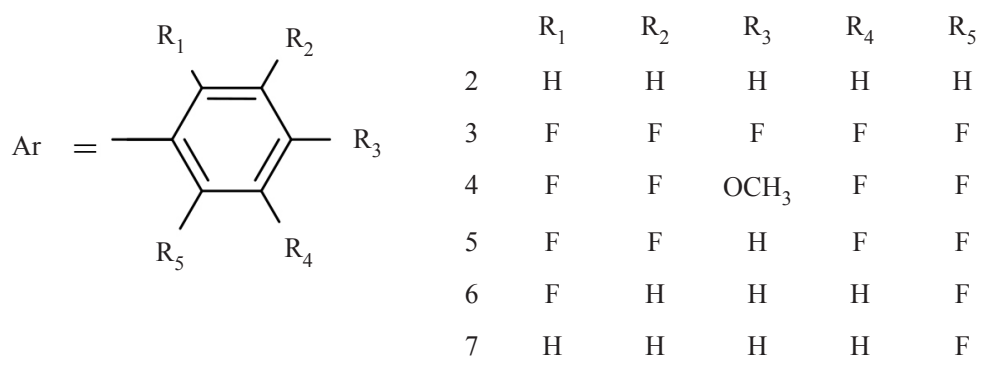

Figure 1. Synthesis and structures of compounds 2-7

Compound $\mathbf{2}$ has only the benzyl moiety and has no fluorine atom at any positions in the aromatic ring. Compounds 3-7 have five, four, four, two and one fluorine atoms, respectively, at various positions in the aromatic ring (Figure 1). The NMR of spectral data of fluorinated benzyl ethers (3-7) were compared with non-fluorinated benzyl ether (2). The carbon atoms $\mathrm{C} 8-\mathrm{C} 11$ (Figure 1) were assigned to the $\mathrm{CH}_{2}$ groups of benzyl moieties of 2 and the fluorinated benzyl moieties of 3-7. For compound 2, the ${ }^{13} \mathrm{C}$ NMR peaks of $\mathrm{C} 8-\mathrm{C} 11$ were observed at chemical shift values at 73.0, 72.1, 75.0 and $73.4 \mathrm{ppm}$, respectively. For compounds 3-7, the ${ }^{13} \mathrm{C}$ NMR peaks of C8-C11 were observed at chemical shift values at 59.9, 58.7, 60.9 and $60.1 \mathrm{ppm} ; 60.0,59.0,61.0$ and $60.5 \mathrm{ppm} ; 60.3,59.2,61.4$ and $60.6 \mathrm{ppm}$; 60.8, 59.4, 61.8 and $60.6 \mathrm{ppm}$ and 66.9, 65.5, 68.6 and $66.7 \mathrm{ppm}$, respectively (Table 1). From these chemical shift values, it was apparent that the $\mathrm{CH}_{2}$ groups of 3-7 resonated at a high field region compared to the non-fluorinated benzyl moieties of $\mathbf{2}$. In other words, the introduction of fluorine atoms onto the aromatic rings caused a net shielding effect on the methylene carbons of fluorinated benzyl moieties. Therefore, the peaks were shifted to the high field region and minimized the peak crowding between 70.0 and $75.0 \mathrm{ppm}$. In fact, most of the methylene peaks of the nonfluorinated benzyl moieties and monosaccharide ring carbons were observed in this region. It was also noticed that $\mathbf{3}$ has pentafluorinated benzyl moieties and its methylene carbon peaks resonated at significantly lower chemical shift values at $60.1 \mathrm{ppm}$ in the ${ }^{13} \mathrm{C}$ NMR compared to methylene groups of other fluorinated benzyl moieties of 4-7. Compounds 4 and 5 have tetrafluorinated benzyl moieties and resonated at 59.0 and 61.4 ppm, which exhibited comparable chemical shift values to each other. Although there was only a small change in chemical shift values in these cases, the peaks were well resolved from each other. Compound $\mathbf{6}$ has difluorinated benzyl moieties that resonated between 59.4 and 
$61.8 \mathrm{ppm}$, and these chemical shift values are also comparable to each other but shows well-resolved peaks. Compound 7 has monofluorinated benzyl moieties at one of the ortho positions, which resonated at higher chemical shift values between 65.5 and $68.6 \mathrm{ppm}$ and showed the highest chemical shift values among all fluorinated benzyl moieties of 3-7. Comparably, the changes in chemical shift values in 7 were relatively small but sufficient enough to reduce the peak crowding at the region between 70.0 and $75.0 \mathrm{ppm}$. In this study, we understood that at least one fluorine atom was required in the ortho position on the aromatic ring of benzyl moieties to cause $\mathrm{CH}_{2}$ groups to resonate at the high field region. The chemical shift difference was found to be $\sim 20.0 \mathrm{ppm}$ if both ortho positions are fluorinated. This difference in chemical shift value was sufficient to reduce the peak crowding between $72.0-75.0 \mathrm{ppm}$ in the ${ }^{13} \mathrm{C}$ NMR spectra, whcih rendered the interpretation of the spectra more easily.

Table 1. ${ }^{13} \mathrm{C}$ NMR spectral data of compounds $2-7$ in $\mathrm{C}_{6} \mathrm{D}_{6}$

\begin{tabular}{|c|c|c|c|c|c|c|}
\hline \multirow{2}{*}{ Position } & \multicolumn{6}{|c|}{$\delta_{\mathrm{C}}(\mathrm{ppm})$} \\
\hline & 2 & 3 & 4 & 5 & 6 & 7 \\
\hline 1 & 99.4 & 99.0 & 99.0 & 99.0 & 99.5 & 99.2 \\
\hline 2 & 75.7 & 76.5 & 76.5 & 76.6 & 76.8 & 76.2 \\
\hline 3 & 80.8 & 81.1 & 81.0 & 81.3 & 81.5 & 81.0 \\
\hline 4 & 75.5 & 74.5 & 74.5 & 74.9 & 75.7 & 75.3 \\
\hline 5 & 72.7 & 72.1 & 72.0 & 72.2 & 72.5 & 72.5 \\
\hline 6 & 70.0 & 69.5 & 69.5 & 69.7 & 70.4 & 70.1 \\
\hline 7 & 54.4 & 54.5 & 54.5 & 54.5 & 54.3 & 54.3 \\
\hline 8 & 73.0 & 59.9 & 60.0 & 60.3 & 60.8 & 66.9 \\
\hline 9 & 72.1 & 58.7 & 59.0 & 59.2 & 59.4 & 65.5 \\
\hline 10 & 75.0 & 60.9 & 61.0 & 61.4 & 61.8 & 68.6 \\
\hline 11 & 73.4 & 60.1 & 60.5 & 60.6 & 60.6 & 66.7 \\
\hline $\begin{array}{l}\text { Aromatic } \\
\text { ring } \\
\text { carbons }\end{array}$ & $\begin{array}{l}128.1-128.5 \text { (ortho) } \\
127.7-127.9 \text { (meta) } \\
127.4-127.6 \text { (para) } \\
139.1-139.5 \text { (ipso) }\end{array}$ & $\begin{array}{l}145.7 \text { (ortho) } \\
137.5 \text { (meta) } \\
141.2 \text { (para) } \\
111.3 \text { (ipso) }\end{array}$ & $\begin{array}{c}146.1 \text { (ortho) } \\
140.1-141.1 \text { (meta) } \\
138.6-139.0 \text { (para) } \\
109.9 \text { (ipso) }\end{array}$ & $\begin{array}{l}145.8 \text { (ortho) } \\
145.3 \text { (meta) } \\
105.8(\text { para }) \\
117.2(\text { ipso) }\end{array}$ & $\begin{array}{c}162.3 \text { (ortho) } \\
129.6-130.1 \text { (meta) } \\
110.9-111.3 \text { (para) } \\
114.8-115.0 \text { (ipso) }\end{array}$ & $\begin{array}{c}129.9-130.5 \text { (ortho with } \mathrm{H} \text { ) } \\
160.7-161.0 \text { (ortho with } \mathrm{F}) \\
128.9-129.3 \text { (meta) } \\
123.9-126.5 \text { (para) } \\
114.9-115.2 \text { (ipso) }\end{array}$ \\
\hline $\begin{array}{l}\text { Methoxy } \\
\text { carbons } \\
\text { at para } \\
\text { psotions }\end{array}$ & - & - & $69.5\left(p-\mathrm{OCH}_{3} \times 4\right)$ & - & - & - \\
\hline
\end{tabular}

The ${ }^{13} \mathrm{C}$ NMR chemical shift values of $\mathrm{C} 1-\mathrm{C} 11$ in spectra of 2-7 are summarized in Table 1 . The aromatic ring carbons of 2 resonated at 128.1-128.5, 127.7-127.9, 127.4-127.6 and 139.1-139.5 ppm, respectively, for ortho, meta, para and ipso positions. The ipso carbons resonated at higher chemical shift values than other carbons. In general, the 
fluorinated compounds (3-7) showed higher chemical shift values at ortho, meta and para positions. It is the presence of electronegative fluorine atoms that caused a deshielding effect. The ipso carbon showed lower chemical shift values due to the absence of electronegative fluorine atoms. For example, 3 showed chemical shift values of 145.7, 137.5 and 141.2 ppm for ortho, meta and para positions, respectively; and the ipso position showed a chemical shift value of 111.3 ppm. Compound 4 exhibited deshielding effects at the ortho and meta positions and resonated at 146.1 and 140-141.1 ppm, respectively. The para position was not fluorinated but an electronegative oxygen atom from the methoxy group was attached to it. Therefore, it was deshielded and resonated at 138.6-139.0 ppm, and the ipso position resonated at $109.9 \mathrm{ppm}$. The four methoxy groups resonated at $69.5 \mathrm{ppm}$. Compound $\mathbf{5}$ showed a deshielding effect at the ortho and meta positions, and resonated at 145.8 and $145.3 \mathrm{ppm}$, respectively. The para position was not deshielded and therefore resonated at $105.8 \mathrm{ppm}$, and the ipso position resonated at $117.2 \mathrm{ppm}$. In 6, both ortho positions were substituted with fluorine. Therefore, these two positions were deshielded and resonated at $162.3 \mathrm{ppm}$; the meta, para and ipso positions resonated at 129.6-139.1, 110.9-111.3 and 114.8-115.0 ppm, respectively. Finally, in 7, one of the ortho positions was fluorinated and the deshielding effect caused these fluorinated carbons to resonate at 160.7-161.0 ppm. The other carbon at ortho position had no fluorine atom and resonated at 129.9-130.5 ppm. The meta, para and ipso positions resonated at 128.9-129.3, 126.2-126.5 and 114.9-115.2 ppm, respectively.

The ${ }^{1} \mathrm{H}-\mathrm{NMR}$ spectra of 2-7 are analyzed for their chemical shift effects and the data are summarised in Table 2. The methyl protons at position 7 attached to the anomeric carbon through methoxy oxygen atoms gave a singlet in all compounds (2-7), resonated at 3.00-3.11 ppm. The monosaccharide ring protons in 2-7 at positions 1-5 and protons at $6 \alpha$ and $6 \beta$ resonated in the usual region between 3.56 and $4.76 \mathrm{ppm}$. Protons at positions $8 \alpha$ and $8 \beta, 9 \alpha$ and $9 \beta, 10 \alpha$ and $10 \beta$ and $11 \alpha$ and $11 \beta$ were assigned for the chemically non-equivalent methylene protons of benzyl moieties in 2 and fluorinated benzyl moieties in 3-7. In general, the chemical shift variations of these protons were not significant and comparable among themselves. However, 6 and $\mathbf{7}$ showed somewhat higher chemical shift values relative to $\mathbf{2}$ (Table 2). In 6, both ortho positions were substituted with fluorine atoms and in 7 one of the ortho positions was substituted with a fluorine atom. The aromatic ring protons of 2 resonated at 7.11-7.14, 7.22-7.35 and 7.04-7.97 ppm, respectively for ortho, meta and para positions. Compound $\mathbf{3}$ did not give any peak at this region since all positions were substituted by fluorine atoms. Compound $\mathbf{4}$ also did not give any peaks at this region since ortho and meta positions were fluorinated and the para positions were substituted by methoxy groups. The methyl protons from these methoxy groups gave singlets at 3.42-3.48 ppm. Both ortho and both meta positions of $\mathbf{5}$ were fluorinated and the lonely proton at para positions gave a peak at 6.10-6.24 ppm. In 6, both ortho positions were substituted with fluorine atoms and the protons at meta and para positions gave peaks at 6.49-6.61 and 6.39-6.45 ppm, respectively. Finally, in 7 one of the ortho positions was fluorinated and the proton at other ortho positions resonated between 7.30-7.60 ppm and the protons at meta and para positions resonated at 6.71-6.77 and 6.79-6.83 ppm, respectively. Overall, the ${ }^{1} \mathrm{H}-\mathrm{NMR}$ chemical shift changes were not significant. The ${ }^{19}$ F-NMR of 3-7 were also acquired and they resonated between -115.0 and -164.0 ppm (refer to Spectral data in the Experimental details section).

As pointed out previously in the synthesis of oligosaccharides, the benzyl moiety has frequently been used as the protecting group to protect the hydroxyl groups present in the monosaccharide units. ${ }^{15-17}$ However, there has been a ${ }^{1} \mathrm{H}$ and ${ }^{13} \mathrm{C}$ NMR spectral overlap of methylene peaks of benzyl moieties due to monosaccharide cores. ${ }^{15-17}$ Additionally, the spectral complexity increases with the increasing monosaccharide units. Particularly, there has been an overlap of one peak due to monosaccharide cores, which resonated at $65-85 \mathrm{ppm}$ in the ${ }^{13} \mathrm{C} \mathrm{NMR}$ spectra, and another peak due to the methylene group of the benzyl moiety, which resonated at 72-75 ppm. Our literature search also showed that the introduction of fluorine atom on the aromatic ring of benzyl moiety caused the methylene carbon of benzyl moiety to a shift approximately at $20 \mathrm{ppm}$ to a high field region in the ${ }^{13} \mathrm{C}$ NMR spectra. ${ }^{18}$ Therefore, based on this observation, we have chosen this particular parameter for this current study in order to get the enhanced spectral resolution. We synthesized various fluorinated benzyl ethers. Our study proved that the methylene group of these fluorinated benzyl ethers shifted to the high field region significantly in the ${ }^{13} \mathrm{C}$ NMR spectra and therefore, enhanced the spectral resolution. There was a consistent change in chemical shift values in the methylene carbons of various fluorinated benzyl ethers, mainly due to the presence of a number of fluorine atoms at various positions and the presence or absence of other functional groups at various positions in the aromatic rings. 


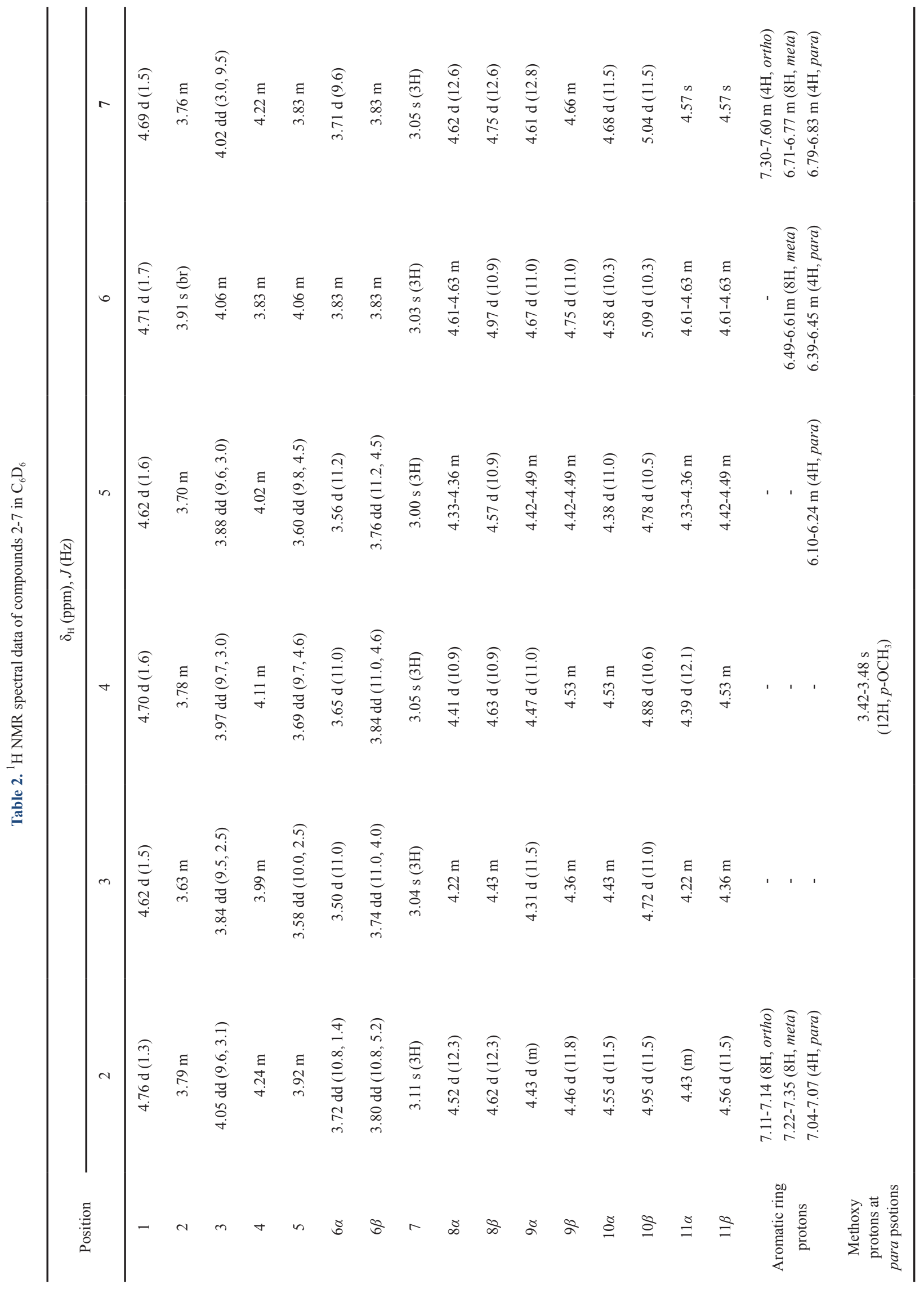




\section{Conclusions}

Benzyl ether (2) and fluorinated benzyl ethers (3-7) were synthesized by the reaction of methyl- $\alpha$-Dmannopyronoside (1) with various benzyl bromides using Williamson ether synthesis method. The spectral analysis showed that the methylene carbons of the fluorinated benzyl ethers showed a significant shift to a high field region compared to the methylene carbons of non-fluorinated benzyl ether in the ${ }^{13} \mathrm{C}$ NMR spectra. As a result, the spectral complexity decreased and enhanced spectral resolution. In this study, we concluded that fluorinated benzyl ethers could be a suitable alternative to non-fluorinated benzyl ethers to protect the hydroxyl groups of monosaccharides in the synthesis of oligosaccharides. Further studies on other monosaccharides can be carried out using fluorinated benzyl ethers as the protecting group. Additionally, biologically and pharmaceutically important oligosaccharides can be synthesized with the help of fluorinated benzyl ethers as the protecting group.

\section{Conflicts of interests}

The authors declare no conflict of interest.

\section{Acknowledgments}

The authors are grateful to the Department of Chemistry, Durham University, UK and the Department of Chemistry and Chemical Technology, The National University of Lesotho, Lesotho for their overall support. This study was extracted from the first author's M.Sc. dissertation research work Department of Chemistry, Durham University, United Kingdom.

\section{References}

[1] Barkley, A.; Arya, P. Chem. Eur. J. 2001, 7(3), 555-563.

[2] Davis, B. G.; Jones, J. B. Synlett. 1999, 1999(9), 1495-1507.

[3] Zheng, T.; Peleen, D.; Smith, L. M. J. Am. Chem. Soc. 2005, 127(28), 9982-9983.

[4] Varki, A. Glycobiol. 1993, 3(2), 97-130.

[5] Dwek, R. A. Chem. Rev. 1996, 96(2), 683-720.

[6] Ali, A.; van den Berg, R.; Overkleeft, H. S.; Filippov, D. V.; van der Marel, G. A.; Codee, J. Tetrahedron Lett. 2009, 50, 2185-2188.

[7] Litjens, R. E. J. N.; Van den Bos, L. J.; Codee, J. D. C.; Overkleeft, H. S.; Van der Marel, G. A. Carbohydr. Res. 2007, 342, 419-429.

[8] Crich, D.; Dudkin, V. J. J. Am. Chem. Soc. 2001, 123(28), 6819-6825.

[9] Yu, H.; Williams, D. L.; Ensley, H. E. Tetrahedron Lett. 2005, 46, 3417-3421.

[10] Jian, G.; Xin-Shan, Y. Molecules. 2010, 15, 7235-7265.

[11] Dhanawat, M.; Shrivastava, S. K. Mini-Rev. Med. Chem. 2009, 9, 169-185.

[12] Smoot, J. T.; Demchenko, A. V. Adv. Carbohydr. Chem. Biochem. 2009, 62, 161-250.

[13] Timmer, M. S. M.; Stocker, B. L.; Northcote, P. T.; Burkett, B. A. Tetrahedron Lett. 2009, 50, 7199.

[14] Amstrong, G. S.;. Mandelshtam, V. A.; Shaka, A. J.; Bendiak, B. J. Magn. Reson. 2005, 173(1), 160-168.

[15] Agrawal, P. K. Phytochemistry. 1992, 31(10), 3307-3330.

[16] Duus, J. O.; Gotfredsen, C. H.; Bock, K. Chem. Rev. 2000, 100(12), 4589-4614.

[17] Blundell, C. D.; Reed, M. A. C.; Overduin, M.; Almond, A. Carbohydr. Res. 2006, 341(12), 1985-1991.

[18] Pouchert, C. J.; Behnke, J. The Aldrich library of carbon-13 and proton FT NMR spectra; Aldrich Chemical Company Inc., 1993; pp 63-130B.

[19] Koto, S.; Morishima, N.; Miyata, Y.; Sen, S. Bull. Chem. Soc. Jpn. 1976, 49(9), 2639-2640.

[20] Robertson, J. Protecting group chemistry; OUP, Oxford, 2002. 